\title{
Measurement techniques for identifying and quantifying hydroxymethanesulfonate (HMS) in an aqueous matrix and particulate matter using aerosol mass spectrometry and ion chromatography
}

\author{
Eleni Dovrou ${ }^{1}$, Christopher Y. Lim ${ }^{2}$, Manjula R. Canagaratna ${ }^{3}$, Jesse H. Kroll ${ }^{2}$, Douglas R. Worsnop ${ }^{3}$, and \\ Frank N. Keutsch ${ }^{1,4,5}$ \\ ${ }^{1}$ John A. Paulson School of Engineering and Applied Sciences, Harvard University, Cambridge, MA 02138, USA \\ ${ }^{2}$ Department of Civil and Environmental Engineering, Massachusetts Institute of Technology, Cambridge, MA 02138, USA \\ ${ }^{3}$ Center for Aerosol and Cloud Chemistry, Aerodyne Research, Inc., Billerica, MA 02138, USA \\ ${ }^{4}$ Department of Chemistry and Chemical Biology, Harvard University, Cambridge, MA 02138, USA \\ ${ }^{5}$ Department of Earth and Planetary Sciences, Harvard University, Cambridge, MA 02138, USA
}

Correspondence: Eleni Dovrou (edovrou@g.harvard.edu)

Received: 29 March 2019 - Discussion started: 7 May 2019

Revised: 3 September 2019 - Accepted: 5 September 2019 - Published: 7 October 2019

\begin{abstract}
Oxidation of sulfur dioxide $\left(\mathrm{SO}_{2}\right)$ in the gas phase and in cloud and fog water leads to the formation of sulfate that contributes to ambient particulate matter (PM). For severe haze events with low-light conditions, current models underestimate the levels of sulfate formation that occur exclusively via the oxidation of sulfur dioxide. We show here that measurement techniques commonly used in the field to analyze PM composition can fail to efficiently separate sulfur-containing species, resulting in the possible misidentification of compounds. Hydroxymethanesulfonate (HMS), a sulfur(IV) species that can be present in fog and cloud water, has been largely neglected in both chemical models and field measurements of PM composition. As HMS is formed without oxidation, it represents a pathway for $\mathrm{SO}_{2}$ to contribute to PM under low-light conditions. In this work, we evaluate two techniques for the specific quantification of HMS and sulfate in PM, ion chromatography (IC) and aerosol mass spectrometry (AMS). In cases in which the dominant sulfurcontaining species are ammonium sulfate or HMS, differences in AMS fragmentation patterns can be used to identify HMS. However, the AMS quantification of HMS in complex ambient mixtures containing multiple inorganic and organic sulfur species is challenging due to the lack of unique organic fragments and the variability of fractional contributions of $\mathrm{H}_{x} \mathrm{SO}_{y}^{+}$ions as a function of the matrix. We describe an im-
\end{abstract}

proved IC method that provides efficient separation of sulfate and HMS and thus allows for the identification and quantification of both. The results of this work provide a technical description of the efficiency and limitations of these techniques as well as a method that enables further studies of the contribution of S(IV) versus $\mathrm{S}(\mathrm{VI})$ species to PM under lowlight atmospheric conditions.

\section{Introduction}

\subsection{Sulfur species in cloud and fog water}

Hydroxymethanesulfonate (HMS; $\mathrm{HOCH}_{2} \mathrm{SO}_{3}^{-}$) is the product of the aqueous-phase reaction between dissolved sulfur dioxide $\left(\mathrm{SO}_{2}\right)$ and formaldehyde $(\mathrm{HCHO})$ and is considered an important compound in cloud and fog water (Munger et al., 1986; Dixon and Aasen, 1999; Whiteaker and Prather, 2003). HMS is very stable at low $\mathrm{pH}(\mathrm{pH}<6)$ and is resistant towards oxidation by hydrogen peroxide and ozone; however, it can be oxidized by hydroxyl radicals (Kok et al., 1986; Martin et al., 1989; Chapman et al., 1990). The stability of HMS has a strong $\mathrm{pH}$ dependence as it dissociates at high $\mathrm{pH}$ values. HMS acid is a strong acid, and thus it completely dissociates in water, with a second dissociation 
constant of $\mathrm{pKa}=10.2$ (Reaction R1) (Olson and Hoffmann, 1986, 1989; Betterton et al., 1988; Warneck, 1989; Möller, 2014).

$$
\mathrm{HCHO}+\mathrm{SO}_{3}^{2-} \longrightarrow \mathrm{HCH}(\mathrm{O})^{-} \mathrm{SO}_{3}^{-} \stackrel{\mathrm{H}^{+}}{\rightleftharpoons} \mathrm{HOCH}_{2} \mathrm{SO}_{3}^{-}
$$

HMS formation results in the acidification of cloud droplets and can contribute significantly to aerosol mass and aerosol sulfur concentration at low $\mathrm{pH}$, at which it is stable (Dixon and Aasen, 1999). HMS can be retained in aerosol particles after cloud evaporation if the $\mathrm{pH}$ is greater than 4 .

In cloud and fog water, $\mathrm{SO}_{2}$ reacts with water, producing bisulfite $\left(\mathrm{HSO}_{3}^{-}\right)$when $3<\mathrm{pH}<6$, which further dissociates to form sulfite $\left(\mathrm{SO}_{3}^{2-}\right)$ when $\mathrm{pH}>6$. Bisulfite and sulfite can be oxidized rapidly by several species such as the hydroxyl radical $(\mathrm{OH})$, ozone $\left(\mathrm{O}_{3}\right)$, oxygen $\left(\mathrm{O}_{2}\right)$ and hydrogen peroxide $\left(\mathrm{H}_{2} \mathrm{O}_{2}\right)$ (Hegg and Hobbs, 1982; Lind et al., 1987; Shen et al., 2012); thus, S(IV) species are not expected in PM in significant amounts. The formation of HMS is favorable at high levels of sulfur dioxide and formaldehyde, low levels of oxidants like $\mathrm{OH}, \mathrm{H}_{2} \mathrm{O}_{2}$ and $\mathrm{O}_{3}$ (Hegg and Hobbs, 1982; Lind et al., 1987), and cloud and fog $\mathrm{pH}$ in the range of approximately 4-6 (Munger et al., 1984, 1986). Oxidation of dissolved sulfur dioxide by $\mathrm{O}_{3}$ is significant for $\mathrm{pH}$ values greater than 4 , and oxidation by $\mathrm{H}_{2} \mathrm{O}_{2}$ is considered to be the dominant pathway for the formation of sulfate in cloud and fog water. During haze events oxidant concentrations have been reported to be low, resulting in low oxidation rates, whereas formaldehyde and sulfur dioxide concentrations have been reported to be high (Ji et al., 2014; Rao et al., 2016; Wang et al., 2016). Therefore, the formation of HMS is favorable under these conditions.

Model simulations under low-light conditions in regions with slow photochemistry, such as polluted cities in China and India, underestimate sulfate $\left(\mathrm{SO}_{4}^{2-}\right)$ concentrations measured in the field using ion chromatography (IC) (Wang et al., 2016), indicating that there is either a missing source of $\mathrm{SO}_{4}^{2-}$ in the model or other sulfur-containing species are misidentified as $\mathrm{SO}_{4}^{2-}$ by IC. During 2009 and 2010 two field campaigns were conducted in Germany (Scheinhardt et al., 2014), reporting the presence of HMS in particles produced in urban areas. HMS concentrations were highest during wintertime in particles with a $0.42-1.2 \mu \mathrm{m}$ diameter size range, although concentrations were low, most likely as not all conditions conductive to HMS formation were met; i.e., there were low-light conditions but also low formaldehyde and $\mathrm{SO}_{2}$ concentrations. In January 2013 an extreme winter haze event was recorded over northern China, which resulted in high levels of sulfate measured by IC compared to periods observed before and after the event. The GEOS-Chem chemical transport model (GEOS-Chem CTM) was not able to reproduce the observed $\mathrm{SO}_{4}^{2-}$ concentrations during the haze events despite good performance during other periods, as it underpredicted $\mathrm{SO}_{4}^{2-}$ concentrations by a factor of 4 during the haze periods. Specifically, the model estimated $\mathrm{SO}_{4}^{2-}$ concentrations to be similar for haze and non-haze periods. This suggests that there might be a significant missing source of $\mathrm{SO}_{4}^{2-}$ (Wang et al., 2014). Wang et al. (2014) suggested that a new heterogeneous pathway of $\mathrm{SO}_{4}^{2-}$ formation could explain the missing $\mathrm{SO}_{4}^{2-}$. Moch et al. (2018) suggested the contribution of HMS to explain the high observed $\mathrm{SO}_{4}^{2-}$ concentrations during these low-light haze events with slow photochemistry. In order to distinguish the two hypotheses, i.e., condensed-phase reactions producing sulfate or contributions from HMS, measurement techniques that allow for quantitative speciated measurements of HMS and sulfate are needed.

The measurement of sulfate in ambient PM is common, whereas measurements of HMS have mainly been conducted for fog and cloud water. Studies reporting the presence of HMS in ambient PM using single-particle mass spectrometry have also been conducted (Neubauer et al., 1996, 1997; Whiteaker and Prather, 2003; Lee et al., 2003; Dall'Osto et al., 2009). Two main methods have been used: ion chromatography (IC) and mass spectrometry (MS). For IC a characteristic elution time is used for the identification of different ions, including sulfate. For MS the detailed mass spectrum, especially differences in fragmentation patterns, can provide a means to differentiate, in this case, different sulfurcontaining species. Moreover, for MS, cations can be observed simultaneously in addition to sulfur-containing ions, whereas for IC a specified IC column with high sensitivity for sulfur-containing ions has to be used to identify them. In order to distinguish HMS from sulfate using IC or MS, the elution times or the mass spectra and fragmentation patterns, respectively, have to be distinct (Munger et al., 1986; Chapman et al., 1990; Neubauer et al., 1996, 1997; Dixon and Aasen, 1999; Zuo and Chen, 2003; Lee et al., 2003; Whiteaker and Prather, 2003; Dall'Osto et al., 2009).

Sulfate is traditionally measured using IC, but for measurements of PM little attention has been given to the effect of HMS in PM on sulfate measurements. An IC system with an alkanol quaternary ammonium analytical column is widely used to separate the main inorganic ions, i.e., $\mathrm{SO}_{4}^{2-}$, $\mathrm{NO}_{3}^{-}, \mathrm{Cl}^{-}$and $\mathrm{Br}^{-}$(Hegg and Hobbs, 1982; Wang et al., 2005; Shen et al., 2012). Single-particle mass spectrometry (SPMS) and an Aerodyne aerosol mass spectrometer (AMS) have been used to detect sulfate (Jimenez, 2003; Murphy et al., 2006; Ji et al., 2014). SPMS and AMS are used for online and offline analysis. During online analysis ambient air is sampled through an inlet to the instrument. For offline analysis, filters collect particles from ambient air; the collected material is extracted into water and after additional dilution the extracts are atomized for analysis via SPMS or AMS.

A variety of technical methods have been used to detect HMS, mainly IC using specific columns (Munger et al., 1986; Dixon and Aasen, 1999), reverse-phase ion pair highperformance liquid chromatography (HPLC) (Zuo and Chen, 
2003), electrospray ionization-tandem mass spectrometry (ESI-MS) (Chapman et al., 1990) and single-particle mass spectrometry (single-particle analysis by laser mass spectrometry - PALMS; rapid single-particle mass spectrometer - RSMS; aerosol time-of-flight mass spectrometer ATOFMS) (Neubauer et al., 1996, 1997; Lee et al., 2003; Whiteaker and Prather, 2003; Dall'Osto et al., 2009). In this work we present an IC method specifically developed to identify and quantify HMS, and we discuss the ability of the AMS to identify and quantify HMS in the presence of sulfate and different cations to evaluate the matrix effects under laboratory conditions. In addition, we compare these methods with the technical methods used in previous work.

\subsection{Previous work identifying HMS using single-particle mass spectrometry, capillary electrophoresis and reverse-phase HPLC}

Mass spectrometry has been used in the past to identify HMS. Chapman et al. (1990) reported its identification by using an electrospray ionization mass spectrometer (ESI-MS). The characteristic $m / z$ ratio was determined to be $m / z=111$ $\left(\mathrm{HOCH}_{2} \mathrm{SO}_{3}^{-}\right)$; to determine a distinct dissociation pattern for HMS the collision-induced dissociation spectrum showed that $m / z=80\left(\mathrm{SO}_{3}^{-}\right)$and $m / z=81\left(\mathrm{HSO}_{3}^{-}\right)$can be used as characteristic fragment ions for HMS detection. To quantify HMS, $m / z=81\left(\mathrm{HSO}_{3}^{-}\right)$was used as its corresponding peak was larger than $m / z=80\left(\mathrm{SO}_{3}^{-}\right)$and it showed a linear relationship between concentration and ion signal in the ESIMS. However, this method may result in noisy spectra for concentrations below $1 \mathrm{ppb}$, and as discussed later $\mathrm{m} / \mathrm{z}=81$ $\left(\mathrm{HSO}_{3}^{-}\right)$is not specific to HMS but rather requires the use of tandem mass spectrometry. Chapman et al. (1990) conducted an exploratory study, reporting that the quantitative detection limit for HMS can be on the order of $100 \mu \mathrm{g} \mathrm{m}^{-3}$ for typical sampling conditions using an ESI-MS. Since 1990 there have been advances in the ESI-MS technology that likely result in lower detection limits. However, to our knowledge, these technological changes have not yet provided quantitative evidence of lower detection limits with respect to HMS analysis.

Neubauer et al. $(1996,1997)$ explored the possibility of separating sulfur species, including HMS, by the use of rapid single-particle mass spectrometer (RSMS) in aerosols. Particles are vaporized and ionized by a pulsed laser $(248 \mathrm{~nm})$ and analysis is completed by a reflectron time-of-flight mass analyzer. In contrast to ESI-MS, RSMS did not show an $m / z$ ratio of $111\left(\mathrm{HOCH}_{2} \mathrm{SO}_{3}^{-}\right)$and the dominant signal was $m / z=64\left(\mathrm{SO}_{2}^{+}\right)$when dry particles were analyzed. The $m / z=111\left(\mathrm{HOCH}_{2} \mathrm{SO}_{3}^{-}\right)$ion was observed only in the case of acidic aqueous particles. The single-particle mass spectrometer provides a wider dynamic range and shorter analysis time compared to ESI-MS; however, the quantification can be challenging in aqueous matrices due to interference from compounds, such as $\left(\mathrm{NH}_{4}\right)_{2} \mathrm{SO}_{4}$ and methyl sulfonic acid (MSA), present in the sample (Neubauer et al., 1996, 1997). Whiteaker and Prather (2003) used a single-particle aerosol time-of-flight mass spectrometer (ATOFMS), with a desorption-ionization laser at $266 \mathrm{~nm}$, to identify HMS in ambient particles and droplets as a tracer for fog processing. In that work, even though the $m / z=111$ ion was observed in some cases when HMS sodium salt was mixed with ammonium sulfate, the identification of HMS in ambient samples was difficult and resulted in uncertainties in the quantification (Whiteaker and Prather, 2003). During a fog event in London, Dall'Osto et al. (2009) also reported the presence of HMS using an ATOFMS. The $m / z=111\left(\mathrm{HOCH}_{2} \mathrm{SO}_{3}^{-}\right)$and $m / z=81\left(\mathrm{HSO}_{3}^{-}\right)$ions were identified as markers of HMS. Gilardoni et al. (2016) provided the spectrum of HMS using standard samples. During that study HMS was used as a tracer of aqueous chemistry. Single-particle mass spectrometers have been optimized to overcome sensitivity issues by improving the inlet design, reducing the pump configuration, applying a dual-polarity grid-less reflection design and removing secondary coating of aerosols prior to the analysis (Pratt et al., 2009; Hatch et al., 2014). Such changes can result in higher sensitivity (Pratt et al., 2009; Pratt and Prather, 2012; Hatch et al., 2014). The effect of these optimizations on the sensitivity to HMS has not been reported.

Lee et al. (2003) conducted a field campaign measuring the chemical composition of aerosols with $0.35-2.5 \mu \mathrm{M}$ diameter during the 1999 Atlanta Supersite Project. Using a PALMS instrument they identified HMS via the $m / z=$ $111\left(\mathrm{HOCH}_{2} \mathrm{SO}_{3}^{-}\right)$ion. Methylsulfate $\left(\mathrm{CH}_{3} \mathrm{OSO}_{3}^{-}\right)$was also identified by the $m / z=111$ ion; however, the authors concluded that due to the low acid concentrations in the particles and high temperatures in Atlanta, the $m / z=111$ ion could not be assigned to methylsulfate (Lee et al., 2003). Although Song et al. (2019) stated that the detection limit of AMS and SPMS for HMS could possibly be lower than the concentration reported by Chapman et al. (1990), $100 \mu \mathrm{g} \mathrm{m}^{-3}$ using ESI-MS, such lower levels of HMS were not able to be detected using these methods. In their study, Song et al. (2019) were able to identify HMS as a component of secondary organic aerosol (SOA) but they could not quantify it, likely for the reasons outlined below in this work.

Overall, the quantification of HMS using single-particle MS methods is challenging due to matrix effects in ambient samples (Neubauer et al., 1996, 1997; Whiteaker and Prather, 2003). The sensitivity challenges of these methods with respect to HMS quantification yield the necessity of further study. Aerosol mass spectroscopy (AMS) was used in this work to investigate the ability to identify and quantify HMS and will be described in detail below. However, all mass spectrometry techniques share the challenge that the majority of the fragments, such as $\mathrm{SO}_{3}^{-}$and $\mathrm{HSO}_{3}^{-}$, are common to different sulfur-containing species, including organic compounds potentially in the measured PM (Ge et al., 2012; Canagaratna et al., 2015; Gilardoni et al., 2016.; Song et al., 
2019), and that the ratios can depend on other compounds present in PM, such as ammonium and other cations.

Scheinhardt et al. (2014) provided evidence of the identification of HMS during two field campaigns conducted in nine sites in Germany using capillary electrophoresis (CE). CE achieved the efficient separation of HMS from other compounds using a voltage of $-30 \mathrm{kV}$, and a $750 \mathrm{mbar}$ hydrodynamic sample injection was applied. Quantification was achieved through indirect UV detection at $260 \mathrm{~nm}$ wavelength and a measurement rate of $20 \mathrm{~Hz}$. The detection limit of HMS was reported as $6-7 \mathrm{ng} \mathrm{m}^{-3}$ and concentrations above this were observed during wintertime. The method resulted in the successful quantification of HMS in concentrations $\geq 18-21 \mathrm{ng} \mathrm{m}^{-3}$. Concentrations in the range of 6$18 \mathrm{ng} \mathrm{m}^{-3}$ were reported; however, this range was characterized as less reliable in the study (Scheinhardt et al., 2014). Dabek-Zlotorzynska et al. $(2002,2005)$ analyzed urban atmospheric aerosol and vehicle-emitted samples using $\mathrm{CE}$ and reported the presence of HMS. Identification and quantification were achieved using two injection modes, pressure and electrokinetic injection modes, for $\mathrm{CE}$ and the detection limits of HMS reported were 0.4 and $0.02 \mu \mathrm{M}$, respectively. The wavelength of the UV detector for indirect detection was at $214 \mathrm{~nm}$ (Dabek-Zlotorzynska et al., 2002). CE may be a method that is highly suitable for the detection of HMS; it has high sensitivity, and the eluent $\mathrm{pH}$ should also prevent the decomposition of HMS.

Reverse-phase ion pair HPLC has successfully been used to separate sulfur species (Zuo and Chen, 2003). A cetylpyridinium-coated $\mathrm{C}_{18}$ column was used for the efficient separation of sulfur species, and the detection was achieved by indirect UV light absorption. Zuo and Chen (2003) reported the separation and quantification of sulfite, sulfate and HMS at the concentration range of 19-430, 6.7-430 and 3.8$430 \mu \mathrm{M}$, respectively. This work provides evidence that ionexchange chromatography can be an efficient method for the separation of sulfur species. Even though mass spectrometry has been widely used for the analysis of sulfur species (Neubauer et al., 1996, 1997; Whiteaker and Prather, 2003), there is indication that chromatography methods could provide an efficient separation of these species (Zuo and Chen, 2003).

\section{Experimental design}

\subsection{Chemicals and sample preparation}

The sodium salt of HMS (Na-HMS) was purchased from Sigma-Aldrich (purity $95 \%)$. Sodium sulfate $\left(\mathrm{Na}_{2} \mathrm{SO}_{4}\right)$ and sodium metabisulfite $\left(\mathrm{Na}_{2} \mathrm{~S}_{2} \mathrm{O}_{5}\right)$ were purchased from Sigma-Aldrich (purity $\geq 99 \%$ in both cases) and used to prepare standards and reference solutions. Sodium metabisulfite was used as a source of bisulfite in the samples as it dissociates rapidly in water to form bisulfite. All solutions were prepared by using filtered Milli-Q water. The samples were analyzed at $25^{\circ} \mathrm{C}$ in the $\mathrm{pH}$ range of 3 to 12 . Six types of samples were prepared to examine all the possible combinations of sulfur-containing species. Solutions containing only sodium sulfate, sodium bisulfite/sulfite, Na-HMS and combinations of Na-HMS with sodium bisulfite/sulfite, Na-HMS with sodium sulfate, and all three sulfur-containing species were prepared and analyzed. Hydrogen chloride and sodium hydroxide were used to control the $\mathrm{pH}$ of the samples.

\subsection{Sample analysis}

\subsubsection{Aerosol mass spectrometry analysis}

The Aerodyne high-resolution time-of-flight aerosol mass spectrometer (HR-ToF-AMS) (DeCarlo et al., 2006) was used to determine the mass spectral signatures of Na-HMS, sodium sulfate and bisulfite. The mass spectra of sodium sulfate, sodium bisulfite and sodium HMS were examined, and the concentration of each solution in the atomizer was $10 \mathrm{mM}$. The $\mathrm{pH}$ of the sample solutions was 6 . In addition, solutions containing $20 \%$ sulfate and $80 \% \mathrm{Na}-\mathrm{HMS}, 40 \%$ sulfate and $60 \% \mathrm{HMS}, 60 \%$ sulfate and $40 \% \mathrm{Na}-\mathrm{HMS}$, and $80 \%$ sulfate and $20 \%$ Na-HMS were analyzed to evaluate the ability of distinguishing the two species at varying sulfate to Na-HMS ratios. A reference spectrum of ammonium sulfate was also used to investigate the matrix effect. The solutions were atomized by a particle generator (TSI 3076) and subsequently dried before being sampled by the AMS. The AMS heater was set at the standard operating temperature of $600{ }^{\circ} \mathrm{C}$. The flow was controlled using an atomizer and the mobility particle diameter was selected at $100 \mathrm{~nm}$ using an electrostatic classifier (TSI 3082).

\subsubsection{Ion chromatography analysis}

A Dionex ICS-5000+ ion chromatography (IC) system was used to analyze the samples. Two pairs of guard and analytical columns were used. The AG12A-AS12A and the AG22AS22 pairs (Dionex Ionpac) were selected in order to examine peak separation when columns with different internal coatings (functional groups) are used. The AG22-AS22 column pair was selected due to the fast analysis of inorganic ions that it provides and its general use for main inorganic anion analysis; it is a standard column used for the measurement of anions in PM via IC. In addition, the AG12AAS12A column pair was selected due to its ability to efficiently separate sulfur species. Both column pairs were selected because of the functional group of the analytical column, the hydrophobicity and their efficiency compared to other commercially available columns. The mobile phase during the experiments was $4.5 \mathrm{mM}: 0.8 \mathrm{mM}$ sodium carbonate to sodium bicarbonate with a flow rate of $1 \mathrm{~mL} \mathrm{~min}^{-1}$. The column and compartment temperatures were both $25^{\circ} \mathrm{C}$, and the delivery speed and delivery sample volume for the 

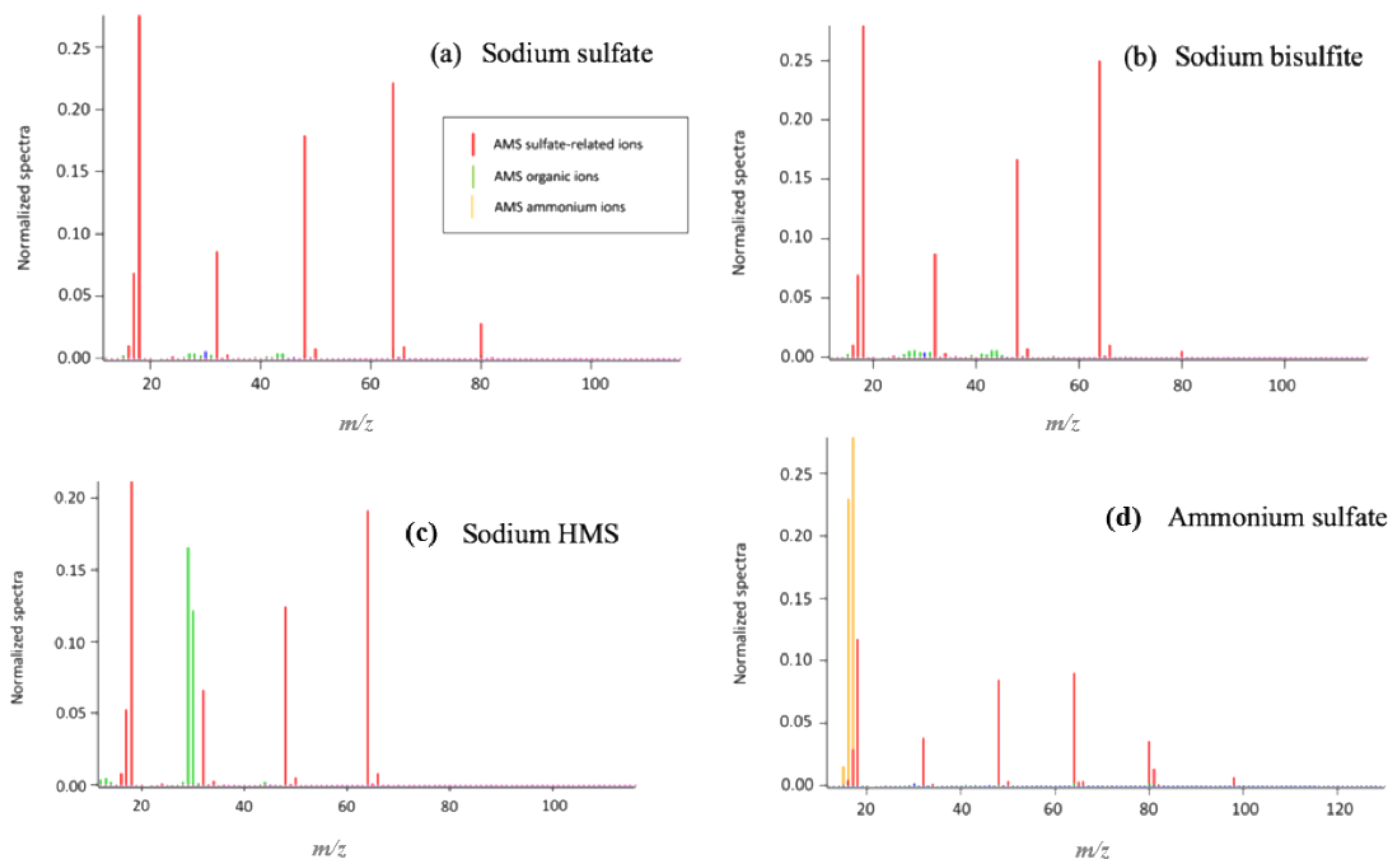

Figure 1. Sample analysis using the HR-ToF-AMS. (a) Sodium sulfate fragmentation. The main peaks are $\mathrm{SO}^{+}(\mathrm{m} / z=48)$ and $\mathrm{SO}_{2}^{+}$ $(m / z=64)$. (b) Sodium bisulfite fragmentation. The spectrum is similar to the sodium sulfate spectrum, indicating that their distinction is not possible. (c) Sodium HMS fragmentation. The main difference that allows for the distinction among HMS, bisulfite and sulfate is the presence of organic ions and the absence of the $\mathrm{SO}_{3}^{+}$ion $(m / z=79.96)$ in the HMS spectrum. (d) Ammonium sulfate fragmentation was used as a reference. Similar to (a), in panels (b) and (c) the main ions are $\mathrm{SO}^{+}(\mathrm{m} / z=48)$ and $\mathrm{SO}_{2}^{+}(\mathrm{m} / z=64)$. Ammonium sulfate is also distinguished from HMS due to the presence of the $\mathrm{SO}_{3}^{+}$ion $(m / z=79.96), \mathrm{HSO}_{3}^{+}$ion $(m / z=80.96)$ and $\mathrm{H}_{2} \mathrm{SO}_{4}^{+}$ion $(m / z=97.97)$. The $\mathrm{pH}$ of all samples was 6 and the temperature $25^{\circ} \mathrm{C}$.

analysis were $4 \mathrm{~mL} \mathrm{~min}^{-1}$ and $4 \mathrm{~mL}$. The sample analysis time was 30 min with HMS, bisulfite and sulfate having retention times in the range of $14-16$ min.

\section{Results and discussion}

\subsection{AMS spectra}

Samples of sodium bisulfite, sulfate and Na-HMS were analyzed individually using the HR-ToF-AMS in order to determine the mass spectral signatures of these compounds (Fig. 1). For Na-HMS the organic ions $\mathrm{CHO}^{+}(m / z=29.00)$ and $\mathrm{CH}_{2} \mathrm{O}^{+}(\mathrm{m} / z=30.01)$ are observed. However, these organic ions are observed from many organic species (Canagaratna et al., 2015) and are not specific signatures of HMS. In contrast, methanesulfonic acid (MSA) has been shown to have unique marker ions that contain carbon and sulfur, such as $\mathrm{CH}_{3} \mathrm{SO}_{2}^{+}(\mathrm{m} / z=78.99)$ and $\mathrm{CH}_{3} \mathrm{SO}_{3}^{+}(\mathrm{m} / z=$ 94.98) (Phinney et al., 2006; Huang et al., 2016; Chen et al., 2019). The unique fragmentation of MSA is attributed to the carbon-sulfur (C-S) bond. Chen et al. (2019) also reported that a variety of organic sulfate-containing compounds that have a $\mathrm{C}-\mathrm{S}$ bond can be distinguished from inorganic sulfate-containing compounds using AMS due to dif- ferences in the fragmentation patterns. In contrast, HMS has a sulfur-carbon-oxygen $(\mathrm{S}-\mathrm{C}-\mathrm{O})$ bond pattern, resulting in lower stability of the molecule. The $\mathrm{C}-\mathrm{S}$ bond of MSA can be retained after ionization, whereas the $\mathrm{S}-\mathrm{C}-\mathrm{O}$ bonds of $\mathrm{HMS}$ fragment either from desorption or ionization, resulting in the unique marker ions of MSA and lack of specific ions for HMS.

The dominant sulfur-containing $\mathrm{H}_{x} \mathrm{SO}_{y}^{+}$ions observed for all samples used in this study were $\mathrm{SO}^{+}(\mathrm{m} / z=47.97)$ and $\mathrm{SO}_{2}^{+}(m / z=63.96)$. Other weaker ions observed in some of the samples include $\mathrm{SO}_{3}^{+}(m / z=79.96), \mathrm{HSO}_{3}^{+}$ $(m / z=80.96)$ and $\mathrm{H}_{2} \mathrm{SO}_{4}^{+}(m / z=97.97)$. The fractional contributions of each of these ions relative to the sum of all the $\mathrm{H}_{x} \mathrm{SO}_{y}^{+}$is shown in Table 1 . The $m / z=111$ ion $\left(\mathrm{HOCH}_{2} \mathrm{SO}_{3}^{-}\right)$, which has been previously assigned as the characteristic parent ion of HMS, is not observed in the AMS spectra due to fragmentation from electron-impact ionization and/or thermal decomposition. As shown in Table 1 and Fig. 1, the difference between HMS spectra and those from the other species is the absence of signals corresponding to $\mathrm{SO}_{3}^{+}, \mathrm{HSO}_{3}^{+}$and $\mathrm{H}_{2} \mathrm{SO}_{4}^{+}$for $\mathrm{HMS}$, which are minor fragment ions for the other species. In previous work the fractional contributions of $\mathrm{SO}^{+}$and $\mathrm{SO}_{2}^{+}$ions have been used as indicators of the presence of HMS in ambient samples 
Table 1. Fractional contributions of $\mathrm{SO}^{+}, \mathrm{SO}_{2}^{+}, \mathrm{SO}_{3}^{+}, \mathrm{HSO}_{3}^{+}$and $\mathrm{H}_{2} \mathrm{SO}_{4}^{+}$to the sum of their intensities in AMS spectra.

\begin{tabular}{|c|c|c|c|c|c|}
\hline Sample & $\begin{array}{c}\mathrm{SO}^{+} \text {fraction } \\
(m / z=47.97)\end{array}$ & $\begin{array}{c}\mathrm{SO}_{2}^{+} \text {fraction } \\
(m / z=63.96)\end{array}$ & $\begin{array}{l}\mathrm{SO}_{3}^{+} \text {fraction } \\
(\mathrm{m} / z=79.96)\end{array}$ & $\begin{array}{l}\mathrm{HSO}_{3}^{+} \text {fraction } \\
(m / z=80.96)\end{array}$ & $\begin{array}{c}\mathrm{H}_{2} \mathrm{SO}_{4}^{+} \text {fraction } \\
(m / z=97.97)\end{array}$ \\
\hline $\begin{array}{l}\text { Sodium sulfate } \\
\left(\mathrm{Na}_{2} \mathrm{SO}_{4}\right)\end{array}$ & $42 \%$ & $56 \%$ & $2 \%$ & $0 \%$ & $0 \%$ \\
\hline $\begin{array}{l}\text { Sodium bisulfite } \\
\left(\mathrm{NaHSO}_{3}\right)\end{array}$ & $38 \%$ & $62 \%$ & $0 \%$ & $0 \%$ & $0 \%$ \\
\hline $\mathrm{Na}-\mathrm{HMS}$ & $40 \%$ & $60 \%$ & $0 \%$ & $0 \%$ & $0 \%$ \\
\hline $\begin{array}{l}\text { Ammonium sulfate } \\
\left(\left(\mathrm{NH}_{4}\right)_{2} \mathrm{SO}_{4}\right)\end{array}$ & $45 \%$ & $46 \%$ & $6 \%$ & $2 \%$ & $1 \%$ \\
\hline $\begin{array}{l}80 \% \mathrm{Na}_{2} \mathrm{SO}_{4} \\
\text { and } 20 \% \mathrm{NaHMS}\end{array}$ & $42 \%$ & $57 \%$ & $1 \%$ & $0 \%$ & $0 \%$ \\
\hline $\begin{array}{l}60 \% \mathrm{Na}_{2} \mathrm{SO}_{4} \\
\text { and } 40 \% \mathrm{Na}-\mathrm{HMS}\end{array}$ & $42 \%$ & $57 \%$ & $1 \%$ & $0 \%$ & $0 \%$ \\
\hline $\begin{array}{l}40 \% \mathrm{Na}_{2} \mathrm{SO}_{4} \\
\text { and } 60 \% \mathrm{Na}-\mathrm{HMS}\end{array}$ & $35 \%$ & $65 \%$ & $0 \%$ & $0 \%$ & $0 \%$ \\
\hline $\begin{array}{l}20 \% \mathrm{Na}_{2} \mathrm{SO}_{4} \\
\text { and } 80 \% \mathrm{Na}-\mathrm{HMS}\end{array}$ & $40 \%$ & $60 \%$ & $0 \%$ & $0 \%$ & $0 \%$ \\
\hline
\end{tabular}

(Ge et al., 2012; Gilardoni et al., 2016; Song et al., 2019). However, as shown in Fig. 1, the $\mathrm{SO}^{+}$and $\mathrm{SO}_{2}^{+}$ions are also the two major fragments of the other species (sodium bisulfite, sodium sulfate and ammonium sulfate), and thus their presence and fractional contributions cannot be used as unique indicators for HMS. For example, as shown in Table 1 , the fractional contributions of the $\mathrm{SO}^{+}$and $\mathrm{SO}_{2}^{+}$ions to the Na-HMS, $\mathrm{NaHSO}_{3}$ and $\mathrm{Na}_{2} \mathrm{SO}_{4}$ spectra are very similar, making distinction challenging. Figure 2 and Table 1 demonstrate that the only clear distinction is a minor fragment from $\mathrm{Na}_{2} \mathrm{SO}_{4}, \mathrm{SO}_{3}^{+}$. However, comparison of the mass spectra of $\left(\mathrm{NH}_{4}\right)_{2} \mathrm{SO}_{4}$ and $\mathrm{Na}_{2} \mathrm{SO}_{4}$ reveals that the relative intensity of $\mathrm{SO}_{3}^{+}$depends strongly on the matrix, in this case the cation, as it is 3 times as large for $\left(\mathrm{NH}_{4}\right)_{2} \mathrm{SO}_{4}$ compared to $\mathrm{Na}_{2} \mathrm{SO}_{4}$. As seen in Table 1, the fractional contributions of the other $\mathrm{H}_{x} \mathrm{SO}_{y}^{+}$fragment ions also depend on the cation. Ammonium sulfate has ion signals at $\mathrm{HSO}_{3}^{+}$and $\mathrm{H}_{2} \mathrm{SO}_{4}^{+}$ that are not present in any of the other species, but Farmer et al. (2010) have shown that organosulfate esters, such as the trihydroxy sulfate ester of isoprene, can also yield $\mathrm{SO}_{3}^{+}$, $\mathrm{HSO}_{3}^{+}$and $\mathrm{H}_{2} \mathrm{SO}_{4}^{+}$ions with relative intensities that are very similar to those observed in ammonium sulfate. In summary, these results show that the lack of truly unique fragments in the HMS spectrum makes the identification and quantification of HMS concentrations from AMS spectra challenging, at least when analyzing complex ambient samples that contain interfering sulfur species such as inorganic sulfates, organic sulfates and inorganic bisulfite species. The most accurate quantification of HMS concentrations is likely to be derived from samples that are dominated by HMS. Chen et al. (2019) reported the difficulty of distinguishing sulfur species due to similarities in fragmentation patterns, which supports the conclusion of this work. The detection of different sulfur organic compounds with AMS is challenging as the fragmentation patterns only have subtle differences and are sensitive to matrix effects.

\subsection{IC chromatographs}

The AG22-AS22 column pair was used to examine the ability to separate HMS and sulfate as well as bisulfite/sulfite and sulfate ions. The AS22 analytical column has the same functional group, alkanol quaternary ammonium, as columns used in previous work for the identification of HMS and for ambient analysis during haze events (Munger et al., 1986; Dixon and Aasen, 1999; Wang et al., 2005; Cao et al., 2014; Cheng et al., 2016). The AS22 analytical column provides a direct comparison to this class of columns. The analytical columns can also be classified with respect to the eluent. The types of columns used in previous studies were the Dionex Ionpac AS11, AS11-HC and AS4A for which AS11 and AS11-HC are anion hydroxide columns and AS4A is an anion carbonate column. The AS22 analytical column (diameter $4 \mathrm{~mm}$ and length $250 \mathrm{~mm}$ of the column) is also classified as an anion carbonate column. Anion hydroxide columns are columns that require a strong base eluent to maintain their sensitivity. In contrast, anion carbonate columns need a neutral eluent.

Six samples containing only sulfate, bisulfite/sulfite, HMS, a combination of HMS with bisulfite/sulfite, HMS with sulfate, and all three sulfur-containing species were analyzed using the AG22-AS22 column pair in a pH range of 3-12. At $\mathrm{pH}$ 3-6 the dissolved sulfur dioxide will be in the form of bisulfite $\left(\mathrm{HSO}_{3}^{-}\right.$) and at $\mathrm{pH}>6$ it will be in the form of sulfite $\left(\mathrm{SO}_{3}^{2-}\right)$. The three $\mathrm{pH}$ values of solution examined were $\mathrm{pH}=3,6$ and 12 , whereas the eluent $\mathrm{pH}$ was $\sim 7$. In all cases sulfate and HMS or sulfate and bisulfite/sulfite were not clearly separated (Fig. 3a and b). In addition, HMS and 

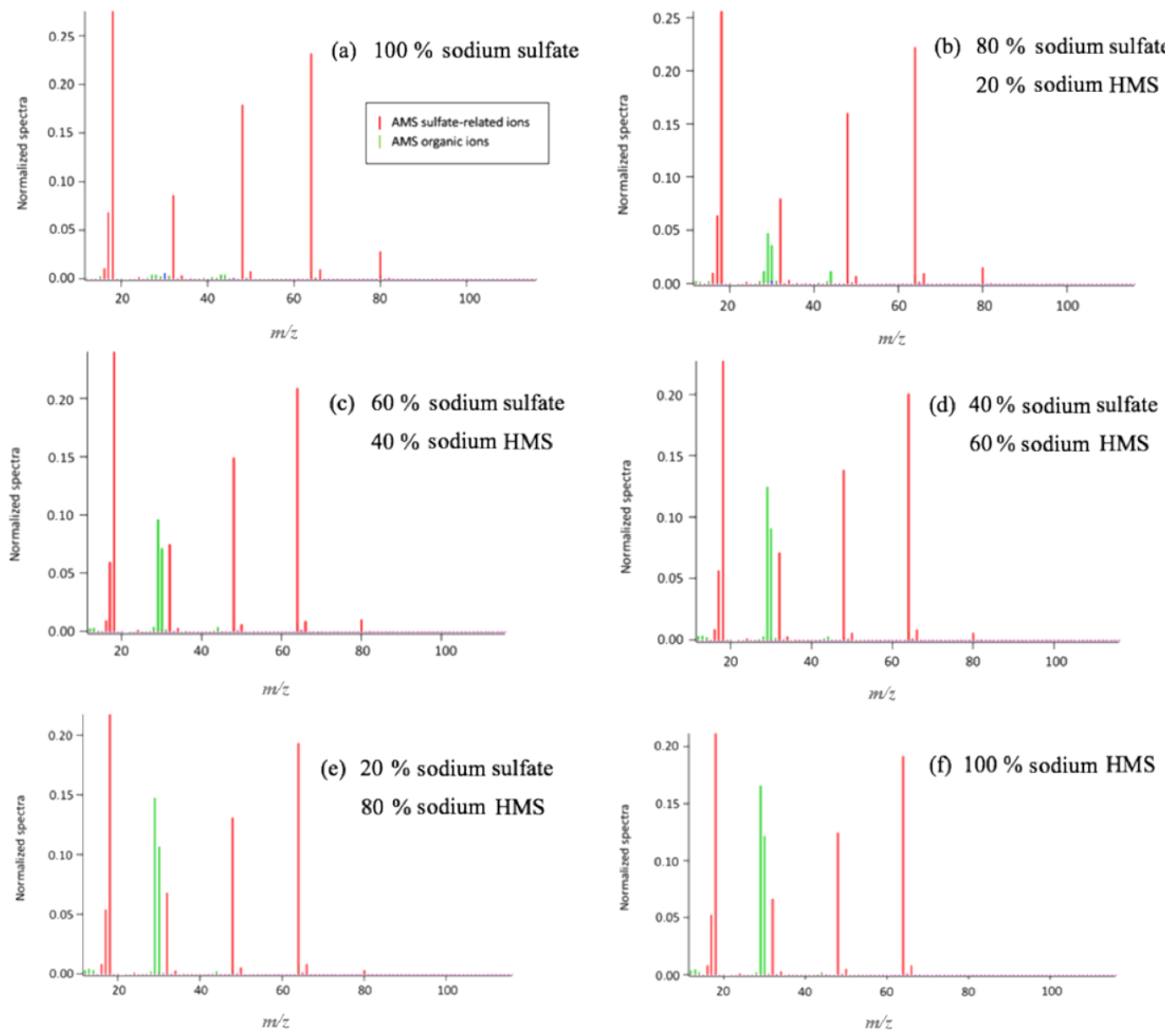

Figure 2. HR-ToF-AMS analysis of aqueous samples containing sodium sulfate and sodium HMS. (a) $10 \mathrm{mM}$ (concentration in the atomizer) of sodium sulfate was analyzed to obtain its signature based on its fragmentation. (b) A sample containing $80 \%$ sodium sulfate and $20 \%$ sodium HMS was analyzed. (c) The sample was prepared with $60 \%$ sodium sulfate and $40 \%$ HMS. Panel (d) presents the fragmentation of a sample with $40 \%$ sodium sulfate and $60 \%$ sodium HMS; (e) $20 \%$ sodium sulfate and $80 \%$ sodium HMS; (f) the fragmentation of the $10 \mathrm{mM}$ HMS sample. An increase in the concentration of HMS results in an increase in the organic ions and a decrease in the $\mathrm{SO}_{3}^{+}$ion $(m / z=79.96)$. The dominant ions, $\mathrm{SO}^{+}(m / z=47.97)$ and $\mathrm{SO}_{2}^{+}(m / z=63.96)$, seem to remain constant. The pH of all samples was 6 and the temperature $25^{\circ} \mathrm{C}$.

bisulfite/sulfite had the same retention time, indicating that their separation is not possible in this system. Each sample analysis was conducted four times with individual sample preparation before each analysis. The area of the peaks was almost identical for sulfate and HMS in all four runs, with a difference only of 0.06 and $0.08 \mathrm{mM}$, respectively.

In order to examine the possibility of separating sulfate and HMS we used the AG12A-AS12A column pair. The AS12A analytical column has an alkyl quaternary ammonium functional group. The AS12A analytical column (diameter $4 \mathrm{~mm}$ and length $200 \mathrm{~mm}$ of the column) is an anion carbonate column, with respect to the eluent, used to analyze inorganic compounds and has the ability to separate sulfur species. The same samples were analyzed under the same conditions, and the column achieved the efficient separation of sulfate and HMS and also sulfate and bisul- fite/sulfite (Fig. 3c and d). HMS and bisulfite/sulfite were not able to be separated as they had the same retention time in this case as well (Fig. 4). The efficiency and the clear separation of peaks that the column provides allow for the quantification of HMS when bisulfite/sulfite is not present.

Calibration standards were prepared and analyzed to determine the retention times (Fig. 5). Each sample was a singlecomponent sample containing only one of the sulfur species. The detection limit of sulfate and HMS was experimentally determined as 0.2 and $0.8 \mu \mathrm{M}$. The equivalent values, assuming the filter collection of ambient samples with a sampling rate of $\sim 80 \mathrm{~L} \mathrm{~min}^{-1}$, a sampling time of $\sim 6 \mathrm{~h}$ and an extraction volume of $20 \mathrm{~mL}$, are $\sim 13$ and $\sim 62 \mathrm{ng} \mathrm{m}^{-3}$. The detection limits were determined by conducting sample runs of different concentrations. The concentration, $\mathrm{C}$, for which the IC could not provide a clear peak was identified and 

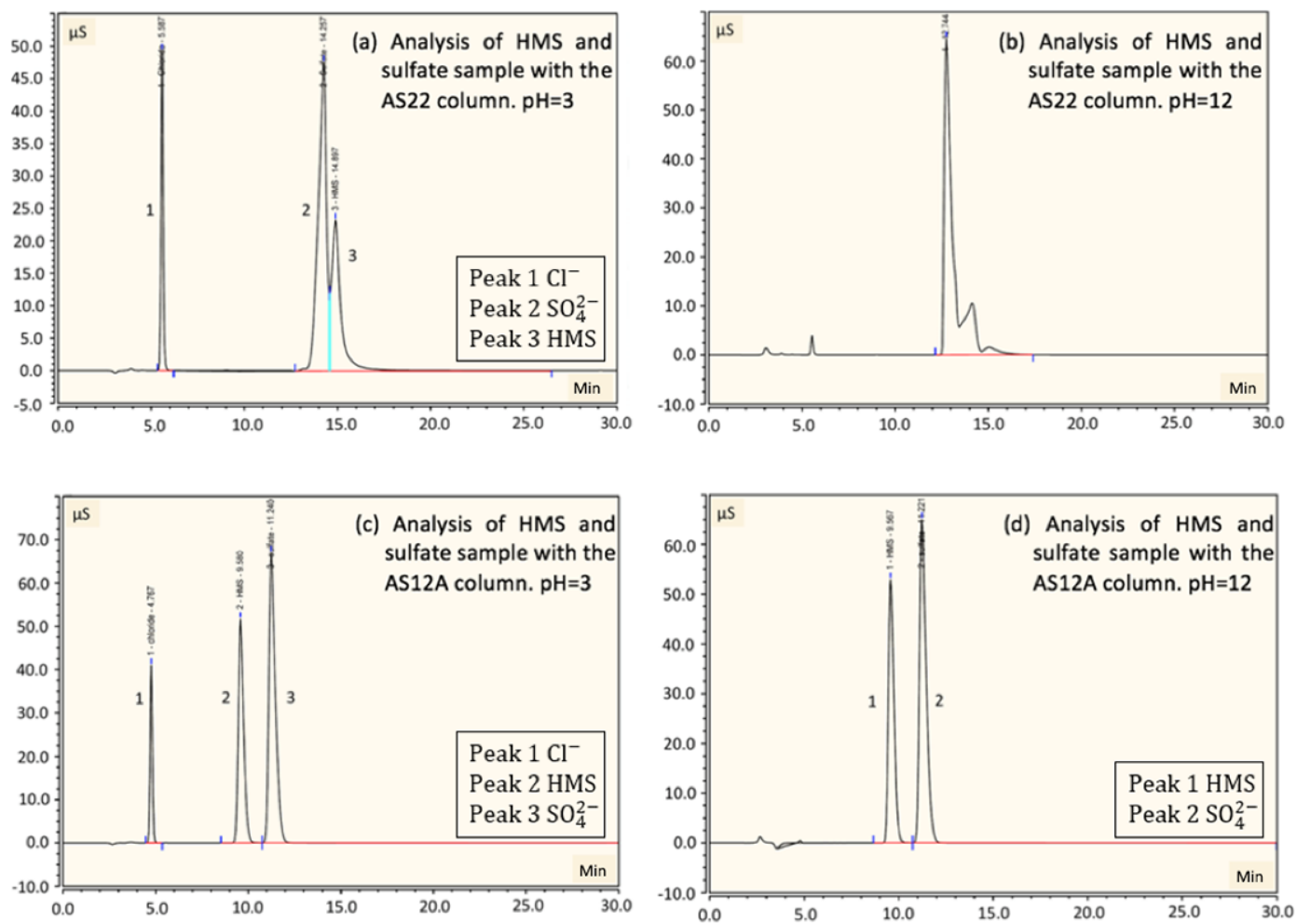

Figure 3. Detection and separation of sulfate and HMS using two ion chromatography systems. The first system, corresponding to (a) and (b), had an AG22 guard column and AS22 analytical column (alkanol quaternary ammonium functional group). The second system, corresponding to (c) and (d), had an AG12A guard column and an AS12A analytical column (alkyl quaternary ammonium functional group). (a) A sample of $2 \mathrm{mM}$ of $\mathrm{HMS}$ and $2 \mathrm{mM}$ of sulfate at $\mathrm{pH}=3$ was analyzed using the AG22-AS22 column pair. Peak 1 represents the chloride at $5.6 \mathrm{~min}$, as $\mathrm{HCl}$ was used to acidify the solution; peak 2 represents the sulfate at 14.3 min and peak 3 represents the HMS at 14.9 min. The separation of sulfate and HMS is not efficient. (b) The same analysis was performed at $\mathrm{pH}=12$, indicating that the column fails to provide clear peaks in basic $\mathrm{pH}$. The analysis was repeated using the AG12A-AS12A column pair in acidic ( $\mathrm{pH}=3$, c) and basic $(\mathrm{pH}=12$ d) conditions. (c) Peak 1 represents the chloride at 4.8 min, peak 2 represents the HMS at 9.6 min and peak 3 represents the sulfate at $11.2 \mathrm{~min}$. (d) Peak 1 represents the HMS at $9.6 \mathrm{~min}$ and peak 2 represents the sulfate at $11.2 \mathrm{~min}$. The results indicate that the column efficiently separates the two species in the cases of both $\mathrm{pH}=3$ and $\mathrm{pH}=12$.
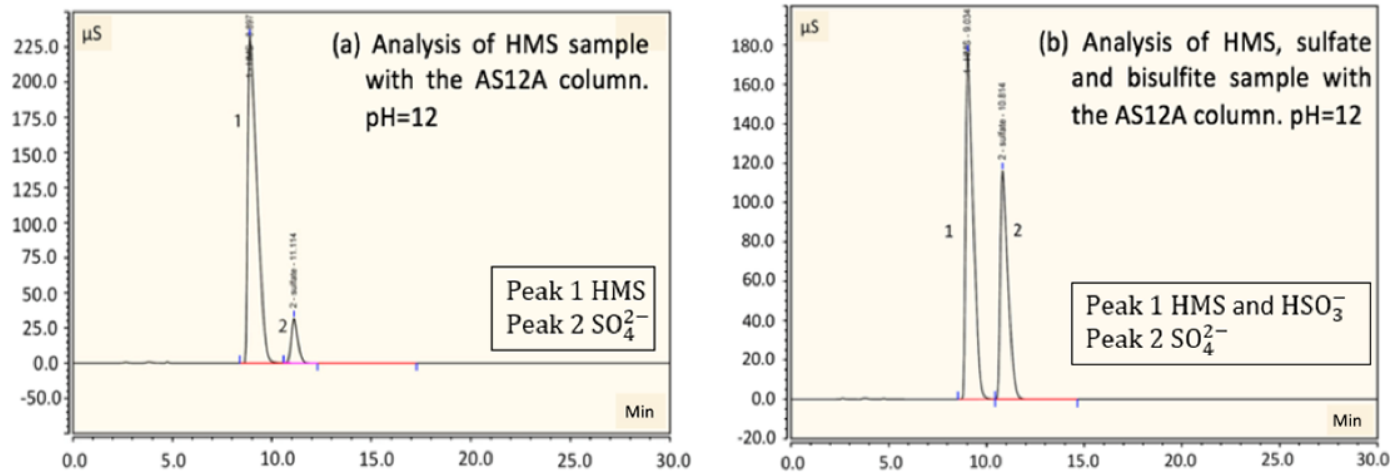

Figure 4. Detection and separation of HMS and sulfate using an ion chromatography system with an AS12A analytical column and AG12A guard column. (a) A sample of $2 \mathrm{mM}$ of HMS at $\mathrm{pH}=12$ was analyzed. A small amount of sulfate is produced due to oxidation by oxygen. The column efficiently separates HMS and sulfate. Peak 1 represents the HMS at 9.6 min and peak 2 represents the sulfate at 11.2 min. (b) A sample of $2 \mathrm{mM}$ of HMS, $2 \mathrm{mM}$ of sulfate and $4 \mathrm{mM}$ of bisulfite at $\mathrm{pH}=12$ was analyzed. Peak 1 represents the HMS at $9.0 \mathrm{~min}$ and peak 2 represents the sulfate at $10.8 \mathrm{~min}$. The separation of sulfate and HMS is efficient; however, separation of bisulfite and HMS was not possible. Samples were examined at $\mathrm{pH}=3$ and 6 as well, with a similar separation efficiency as the aforementioned samples. 
Table 2. Technical characteristics of the columns used for the ion chromatography analysis.

\begin{tabular}{|c|c|c|c|c|c|c|}
\hline $\begin{array}{l}\text { Analytical } \\
\text { column }\end{array}$ & $\begin{array}{l}\text { Guard } \\
\text { column }\end{array}$ & $\begin{array}{l}\text { Functional } \\
\text { group }\end{array}$ & $\begin{array}{l}\text { Eluent } \\
\text { classification }\end{array}$ & $\begin{array}{r}\text { Analytical } \\
\text { column } \\
\text { diameter }(\mathrm{mm})\end{array}$ & $\begin{array}{r}\text { Analytical } \\
\text { column } \\
\text { length }(\mathrm{mm})\end{array}$ & Hydrophobicity \\
\hline AS22 & AG22 & $\begin{array}{l}\text { Alkanol } \\
\text { quaternary } \\
\text { ammonium }\end{array}$ & $\begin{array}{l}\text { Anion } \\
\text { carbonate }\end{array}$ & 4 & 250 & Ultralow \\
\hline AS12A & AG12A & $\begin{array}{l}\text { Alkyl } \\
\text { quaternary } \\
\text { ammonium }\end{array}$ & $\begin{array}{l}\text { Anion } \\
\text { carbonate }\end{array}$ & 4 & 200 & Medium \\
\hline
\end{tabular}

sample runs were conducted for concentrations $\mathrm{C}+\mathrm{n}$, where $n=0.2 \mathrm{mM}$. The concentration for which the baseline and the peak were clearly distinguishable was defined and six runs were conducted for this specific concentration to verify it. The standard deviation of that concentration was estimated. Blank samples were analyzed for each compound, and the mean value and the standard deviation were determined. Considering the $99 \%$ confidence interval, the limit of the blank was calculated as the mean blank value plus the product of the standard deviation of the blank and 2.58, a value that corresponds to the $99 \%$ confidence level (limit of blank $=$ (mean of bank) +2.58 (standard deviation of blank)). The detection limit was estimated as the sum of the limit of the blank and the product of the standard deviation of the low concentration and 2.58 (detection limit $=$ (limit of bank) +2.58 (standard deviation of low concentration)). Standards were prepared before each experiment to ensure their stability and avoid possible decomposition if stored for a prolonged period of time. The retention time of sulfate was 14.2-15.2 min for the system with the AS22 column and 10.8-11.2 min for the system with the AS12A column. The retention time of HMS was 14.8-15.2 and 8.8-9.2 min, respectively. Interestingly, for the HMS and bisulfite individual samples a small amount of sulfate was produced, corresponding to $0.4 \%$ of the total signal due to oxidation from oxygen.

Comparing the results from the two column pairs, it was determined that for the AS22 analytical column the HMS peak appears slightly after the sulfate peak, whereas for the AS12A analytical column the HMS peak appears before the sulfate peak. Using the AS12A analytical column, sulfate represents $55.2 \%$ of the total area signal and HMS $44.8 \%$ when a sample of $2 \mathrm{mM}$ of HMS and $2 \mathrm{mM}$ of sulfate was analyzed. In contrast, for the AS22 analytical column the area signal of sulfate was $63.6 \%$ and HMS was $31.8 \%$ for both $\mathrm{pH}=3$ and 6 . The peaks were connected and there was no baseline separation; thus, the software automatically separated the peaks by a vertical line at the minimum point between them. The software allows for the determination of the baseline, which could result in the quantification of the compounds by elevating the baseline to the minimum point between the connected peaks and disregarding the area be- low. When this was applied a significant underestimation of the concentration, $\gtrsim 15 \%$ HMS with $4 \%$ uncertainty, of the compounds was observed, and therefore the software automatic separation was selected to be used. To be more specific, $4 \%$ uncertainty corresponds to the concentrations measured in multiple runs, and thus the precision of the HMS concentration measurements, and the $\gtrsim 15 \%$ underestimation, is the underestimation of the HMS concentration when a sample containing both sulfate and HMS is analyzed and compared with the HMS concentration of a sample containing only HMS. Therefore, the percent underestimation shows the lack of accuracy of the measurements when these two sample types are analyzed with the AS22 column. The percentages of HMS and sulfate were obtained considering the software separation of the peaks, and the underestimation was determined by obtaining the calibration curves for sulfate and HMS and examining known concentrations. If the concentrations are at lower levels, corresponding to $\lesssim 30 \mu M$ of HMS, the value experimentally estimated under laboratory conditions, which is equivalent to $\lesssim 2 \mu \mathrm{g} \mathrm{m}^{-3}$ assuming the filter collection of ambient samples with a sampling rate of $\sim 80 \mathrm{~L} \mathrm{~min}^{-1}$, a sampling time of $\sim 6 \mathrm{~h}$ and an extraction volume of $20 \mathrm{~mL}$, is used for sample analysis with an aliquot of $4 \mathrm{~mL}$. If sulfate is of an equal or higher concentration, the peaks corresponding to HMS and sulfate have lower area signals and will be treated as one peak. For $\mathrm{pH}=12$ the peaks could not be distinguished. Therefore, when the AS22 analytical column was used the sulfate area signal increased by $8.4 \%$, and the HMS area signal decreased by $13 \%$ compared to the case of the AS12A column.

Considering the intensity of HMS and sulfate for AS12A in the mixed sample, the intensity of the sulfate and HMS peaks was 26.2 and $21.3 \mu \mathrm{S}$ min, respectively, which is the same when HMS and sulfate samples were analyzed individually. In contrast, in the case of AS22, the intensity of the HMS and sulfate peaks was 13.7 and $30.2 \mu \mathrm{S}$ min, respectively. However, when samples containing only HMS and only sulfate were analyzed the intensity was 9.3 and $33.9 \mu \mathrm{S}$ min, respectively. Thus, the intensity of the peak of HMS in the sample that contained both HMS and sulfate was $4.4 \mu \mathrm{S}$ min higher compared to the sample that had only 

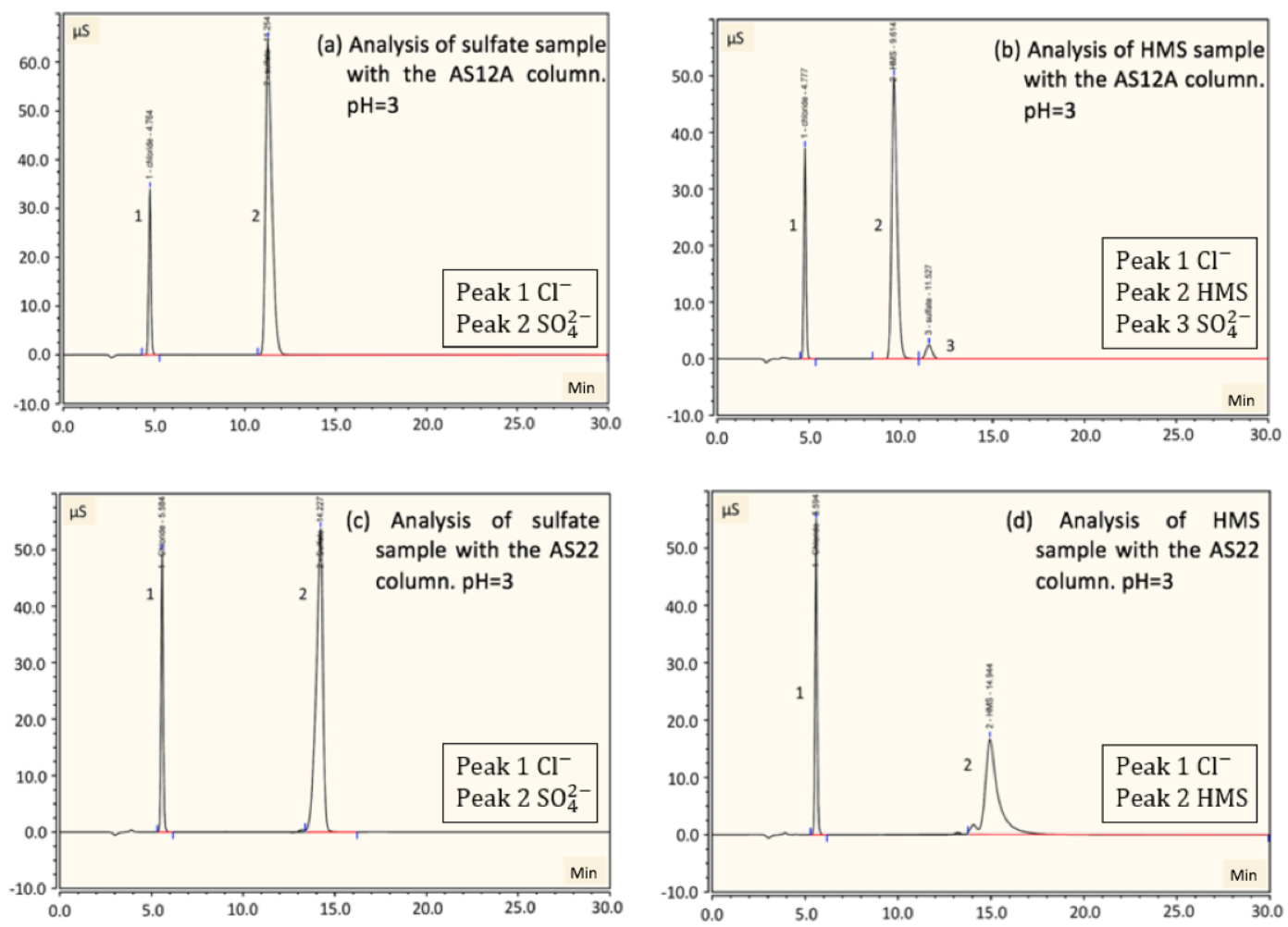

Figure 5. Sample analysis of sulfate and HMS using two ion chromatography systems. The first system, corresponding to (a) and (b), had an AG12A guard column and an AS12A analytical column (alkyl quaternary ammonium functional group). The second system, corresponding to (c) and (d), had an AG22 guard column and AS22 analytical column (alkanol quaternary ammonium functional group). The pH was acidic $(\mathrm{pH}=3)$ and all samples were at room temperature $\left(25^{\circ} \mathrm{C}\right)$. (a) A sample of $2 \mathrm{mM}$ of sulfate was analyzed using the AG12A-AS12A column pair. Peak 1 represents the chloride at $4.8 \mathrm{~min}$, as $\mathrm{HCl}$ was used to acidify the solution, and peak 2 represents the sulfate at $11.3 \mathrm{~min}$. (b) A sample of $2 \mathrm{mM}$ of HMS was analyzed using the AG12A-AS12A column pair. Similarly, peak 1 represents the chloride at 4.8 min and peak 2 represents the HMS at $9.6 \mathrm{~min}$. Interestingly, $0.4 \%$ of HMS is oxidized by oxygen, resulting in the production of sulfate (peak 3). (c) A sample of $2 \mathrm{mM}$ of sulfate was analyzed using the AG22-AS22 column pair. Peak 1 represents the chloride at 5.6 min and peak 2 represents the sulfate at $14.2 \mathrm{~min}$. (d) A sample of $2 \mathrm{mM}$ of HMS was analyzed using the AG22-AS22 column pair. Similarly, peak 1 represents the chloride at $5.6 \mathrm{~min}$ and peak 2 represents the HMS at $14.9 \mathrm{~min}$. Both systems provide the efficient identification of sulfate and the chromatographs represent sulfate with a smooth-shaped peak. In addition, both systems identify HMS; however, the system with the AG22-AS22 column pair indicates that the quantification of HMS might not be possible due to the discontinuous shape of the peak.

HMS. The sulfate peak intensity was $3.7 \mu \mathrm{S}$ min lower in the sample that contained both HMS and sulfate compared to the sample that had only sulfate. Thus, the area signal of the sulfate increased but the intensity of the peak decreased, and the reverse phenomenon was observed for HMS. Considering both the signal contribution and the intensity of the compounds, the results indicate that amounts of both compounds are probably incorporated in both peaks, and since we have an increase in the area of sulfate it is more likely that some of HMS is attributed to sulfate in this analysis.

The AS22 and AS12A columns have different technical characteristics (Table 2). The difference in the retention times is due to the functional groups (internal coating) of the columns and thus their ability to separate ions. Sulfate is more polar than bisulfite/sulfite, and therefore it is expected to have a stronger binding on the stationary phase (functional group), which results in a longer retention time. HMS and bisulfite/sulfite are not separated as they have very similar polarity. In addition, the AS22 analytical column is longer than the AS12A analytical column, which affects the retention time of the examined compounds. The eluent is also a technical aspect that differs between the two columns. The AS12A is an anion carbonate column, and thus the eluent is neutral with respect to the $\mathrm{pH}$, whereas the AS22 column is an anion hydroxide column, and thus the eluent is basic with respect to $\mathrm{pH}$. The stability of HMS has a strong $\mathrm{pH}$ dependence as it dissociates at high $\mathrm{pH}$ values. Therefore, the use of a neutral $\mathrm{pH}$ eluent allows us to avoid HMS decomposition during analysis. The majority of columns with an alkyl quaternary ammonium functional group require a neutral $\mathrm{pH}$ eluent, which results in the efficient separation of sulfur species.

Another factor that can affect the retention time of the compounds is the hydrophobicity of the stationary phase 
of the column. The AS22 analytical column has ultralow hydrophobicity, whereas the AS12A analytical column has medium hydrophobicity, resulting in a more efficient separation of species within a single family. An ultralow hydrophobicity results in faster retention for nonpolar compounds and will cause polar substances of the matrix to accumulate in the column, possibly leading to undesirable effects such as the misidentification of compounds and shifted retention times. Nonpolar compounds will be transferred down the column more readily, whereas polar compounds, such as sulfate and bisulfite/sulfite, might not be eluted efficiently by the eluent, resulting in unrealistic retention times and peak shapes in the chromatograph. This factor can possibly explain the longer retention time of HMS compared to sulfate when the AS22 column is used, as sulfate has a higher polarity than HMS.

\section{Conclusions}

This study investigates techniques used to identify and quantify HMS and sulfate in PM that contains both species. Two main methods were examined: IC and AMS. HMS and sulfate can be efficiently separated and quantified using an IC system with an analytical column that has an alkyl quaternary ammonium functional group (i.e., AS12A). However, using a column with alkanol quaternary ammonium functional groups (i.e., AS22) the quantification of sulfate and HMS is challenging as the peaks are not separated efficiently and they may be identified as one species, typically sulfate. Hence, HMS could possibly be mistaken as sulfate in field measurements. Using an IC system, the detection limit of quantifying HMS and sulfate is 0.8 and $0.2 \mu \mathrm{M}$, respectively; the required concentration needed to distinguish HMS and sulfate was determined to be $>30 \mu \mathrm{M}$ of HMS, and the sulfate concentration has to be lower concentration than that of HMS. These sulfur species can also be distinguished using various mass spectrometry instrumentation if the HMS concentration is high compared to that of other sulfur species present in the analyzed sample. However, the fragments that are used for HMS quantification are common to other sulfur species and are subject to interference from organosulfates and inorganic sulfates. Moreover, this interference can vary with the matrix, in particular cations present in the sample (i.e., $\mathrm{Na}_{2} \mathrm{SO}_{4}$ versus $\left(\mathrm{NH}_{4}\right)_{2} \mathrm{SO}_{4}$ ).

The results obtained in this study may help explain the case of the January 2013 haze event in northern China (Wang et al., 2014) for which models underpredicted sulfate levels compared to observations. During the study of the 2013 haze events, field measurements, analyzed using an alkanol quaternary ammonium column, showed $70 \%-90 \%$ increased sulfate concentrations compared to the model simulations (Wang et al., 2014), and one explanation that has been proposed is that HMS was quantified as sulfate. Similarly, AMS measurements may have identified HMS as sulfate as ex- plained above. This is also consistent with the explanation provided by Moch et al. (2018) and Song et al. (2019).

Applications of both the IC and AMS methods to ambient samples from similar conditions as the January 2013 haze event in the future will provide an opportunity to characterize the efficiency of the identification and quantification of HMS and sulfate in complex mixtures and the degree to which nonoxidative reactions of $\mathrm{SO}_{2}$ contribute to ambient $\mathrm{PM}$, especially for low-light conditions associated with severe haze events. If HMS is not suspected to be present in field samples, it can be overlooked and possibly misidentified as sulfate.

Data availability. The data used within this work are available upon request. Please email Eleni Dovrou (edovrou@g.harvard.edu).

Author contributions. FNK initially conceived of the work. ED developed the specific ion chromatography method described in this work, performed the experiments and analyzed the data. CYL and ED conducted the aerosol mass spectrometry experiments, and CYL, ED and MRC analyzed the data. ED prepared the paper with contributions from CYL, MRC, JHK, DRW and FNK.

Competing interests. The authors declare they have no conflict of interest.

Acknowledgements. The authors thank J. William Munger for helpful statistical and HMS-related discussions, as well as Loretta J. Mickley and Jonathan M. Moch for helpful preliminary discussions.

Financial support. This research has been supported by the Harvard Global Institute.

Review statement. This paper was edited by Pierre Herckes and reviewed by three anonymous referees.

\section{References}

Betterton, E. A., Erel, Y., and Hoffmann, M. R.: AldehydeBisulfite Adducts?: Prediction of Some of Their Thermodynamic and Kinetic Properties, Environ. Sci. Technol., 99, 92-99, https://doi.org/10.1021/es00166a010, 1988.

Canagaratna, M. R., Jimenez, J. L., Kroll, J. H., Chen, Q., Kessler, S. H., Massoli, P., Hildebrandt Ruiz, L., Fortner, E., Williams, L. R., Wilson, K. R., Surratt, J. D., Donahue, N. M., Jayne, J. T., and Worsnop, D. R.: Elemental ratio measurements of organic compounds using aerosol mass spectrometry: characterization, improved calibration, and implications, Atmos. Chem. Phys., 15, 253-272, https://doi.org/10.5194/acp-15-253-2015, 2015. 
Cao, C., Jiang, W., Wang, B., Fang, J., Lang, J., Tian, G., Jiang, J., and Zhu, T. F.: Inhalable microorganisms in Beijing's PM2.5 and PM10 pollutants during a severe smog event, Environ. Sci. Technol., 48, 1499-1507, https://doi.org/10.1021/es4048472, 2014.

Chapman, E. G., Barinaga, C. J., Udseth, H. R., and Smith, R. D.: Confirmation and quantitation of hydroxymethanesulfonate in precipitation by electrospray ionization-tandem mass spectrometry, Atmos. Environ. A-Gen., 24, 2951-2957, https://doi.org/10.1016/0960-1686(90)90475-3, 1990.

Chen, Y., Xu, L., Humphry, T., Hettiyadura, A. P. S., Ovadnevaite, J., Huang, S., Poulain, L., Schroder, J. C., Campuzano-Jost, P., Jimenez, J. L., Herrmann, H., O’Dowd, C., Stone, E. A., and Ng, N. L.: Response of the Aerodyne Aerosol Mass Spectrometer to Inorganic Sulfates and Organosulfur Compounds: Applications in Field and Laboratory Measurements, Environ. Sci. Technol., 53, 5176-5186, https://doi.org/10.1021/acs.est.9b00884, 2019.

Cheng, Y., Bin He, K., Yu Du, Z., Engling, G., Meng Liu, J., Liang Ma, Y., Zheng, M., and Weber, R. J.: The characteristics of brown carbon aerosol during winter in Beijing, Atmos. Environ., 127, 355-364, https://doi.org/10.1016/j.atmosenv.2015.12.035, 2016.

Dabek-Zlotorzynska, E., Piechowski, M., and Keppel-jones, K.: Determination of hydroxymethanesulfonic acid in environmental samples by capillary electrophoresis, J. Separat. Sci., 25, 11231128, 2002.

Dabek-Zlotorzynska, E., Aranda-rodriguez, R., and Graham, L.: Capillary electrophoresis determinative and GC-MS confirmatory method for water-soluble organic acids in airborne particulate matter and vehicle emission Focus Paper, J. Separat. Sci., 28, 1520-1528, https://doi.org/10.1002/jssc.200400053, 2005.

Dall'Osto, M., Harrison, R. M., Coe, H., and Williams, P.: Realtime secondary aerosol formation during a fog event in London, Atmos. Chem. Phys., 9, 2459-2469, https://doi.org/10.5194/acp9-2459-2009, 2009.

DeCarlo, P. F., Kimmel, J. R., Trimborn, A., Northway, M. J., Jayne, J. T., Aiken, A. C., Gonin, M., Fuhrer, K., Horvath, T., Docherty, K. S., Worsnop, D. R., and Jimenez, J. L.: Field-deployable, high-resolution, time-of-flight aerosol mass spectrometer, Anal. Chem., 78, 8281-8289, https://doi.org/10.1021/ac061249n, 2006.

Dixon, R. W. and Aasen, H.: Measurement of hydroxymethanesulfonate in atmospheric aerosols, Atmos. Environ., 33, 2023-2029, https://doi.org/10.1016/S1352-2310(98)00416-6, 1999.

Farmer, D. K., Matsunaga, A., Docherty, K. S., Surratt, J. D., Seinfeld, J. H., Ziemann, P. J., and Jimenez, J. L.: Response of an aerosol mass spectrometer to organonitrates and organosulfates and implications for atmospheric chemistry, P. Natl. Acad. Sci. USA, 107, 6670-6675, https://doi.org/10.1073/pnas.0912340107, 2010.

Ge, X., Zhang, Q., Sun, Y., Ruehl, C. R., and Setyan, A.: Effect of aqueous-phase processing on aerosol chemistry and size distribution in Fresno, California, during wintertime, Environ. Chem., 9, 221-235, https://doi.org/10.1071/EN11168, 2012

Gilardoni, S., Massoli, P., Paglione, M., Giulianelli, L., Carbone, C., Rinaldi, M., Decesari, S., Sandrini, S., Costabile, F., Gobbi, G. P., Pietrogrande, M. C., Visentin, M., Scotto, F., Fuzzi, S., and Facchini, M. C.: Direct observation of aqueous secondary organic aerosol from biomassburning emissions, P. Natl. Acad. Sci. USA, 113, 10013-10018, https://doi.org/10.1073/pnas.1602212113, 2016.
Hatch, L. E., Pratt, K. A., Huffman, J. A., Jimenez, J. L., and Prather, K. A.: Impacts of aerosol aging on laser desorption/ionization in single-particle mass spectrometers, Aerosol Sci. Technol., 48, 1050-1058, https://doi.org/10.1080/02786826.2014.955907, 2014.

Hegg, D. A. and Hobbs, P. V.: Measurements of sulfate production in natural clouds, Atmos. Environ., 16, 2663-2668, https://doi.org/10.1016/0004-6981(82)90348-1, 1982.

Huang, S., Poulain, L., Pinxteren, D. Van, Pinxteren, M. Van, Wu, Z., Herrmann, H., and Wiedensohler, A.: Latitudinal and Seasonal Distribution of Particulate MSA over the Atlantic using a Validated Quantification Method with HR-ToF-AMS, Environ. Sci. Technol., 51, 418-426, https://doi.org/10.1021/acs.est.6b03186, 2016.

Ji, D., Li, L., Wang, Y., Zhang, J., Cheng, M., Sun, Y., Liu, Z., Wang, L., Tang, G., Hu, B., Chao, N., Wen, T., and Miao, H.: The heaviest particulate air-pollution episodes occurred in northern China in January, 2013: Insights gained from observation, Atmos. Environ., 92, 546-556, https://doi.org/10.1016/j.atmosenv.2014.04.048, 2014.

Jimenez, J. L.: Ambient aerosol sampling using the Aerodyne Aerosol Mass Spectrometer, J. Geophys. Res., 108, 8425, https://doi.org/10.1029/2001JD001213, 2003.

Kok, G. L., Gitlin, S. N., and Lazrus, A. L.: Kinetics of the Formation and Decomposition of Hydroxymethanesulfonate, J. Geophys. Res., 91, 2801-2804, https://doi.org/10.1029/JD091iD02p02801,1986.

Lee, S. H., Murphy, D. M., Thomson, D. S., and Middlebrook, A. M.: Nitrate and oxidized organic ions in single particle mass spectra during the 1999 Atlanta Supersite Project, J. Geophys. Res., 108, 1-8, https://doi.org/10.1029/2001jd001455, 2003.

Lind, J. A., Lazrus, A. L., and Kok, G. L.: Aqueous Phase Oxidation of Sulfur(IV) By Hydrogen-Peroxide, Methylhydroperoxide, and Peroxyacetic Acid, J. Geophys. Res., 92, 4171-4177, https://doi.org/10.1029/JD092iD04p04171, 1987.

Martin, L. R., Easton, M. P., Foster, J. W., and Hill, M. W.: Oxidation of hydroxymethanesulfonic acid by Fenton's reagent, Atmos. Environ., 23, 563-568, https://doi.org/10.1016/00046981(89)90005-X, 1989.

Moch, J. M., Dovrou, E., Mickley, L. J., Keutsch, F. N., Cheng, Y., Jacob, D. J., Jiang, J., Li, M., Munger, J. W., Qiao, X., and Zhang, Q.: Contribution of hydroxymethane sulfonate to ambient particulate matter: A potential explanation for high particulate sulfur during severe winter haze in Beijing, Geophys. Res. Lett., 45, 11969-11979, https://doi.org/10.1029/2018GL079309, 2018.

Möller, D.: Chemistry of the Climate System: Fundamentals and Processes, DE GRUYTER, 2014.

Munger, J. W., Jacob, D. J., and Hoffmann, M. R.: The occurrence of bisulfite-aldehyde addition products in fog- and cloudwater, J. Atmos. Chem., 1, 335-350, https://doi.org/10.1007/BF00053799, 1984.

Munger, J. W., Tiller, C., and Hoffmann, M. R.: Identification of hydroxymethanesulfonate in fog water., Science, 231, 247-249, https://doi.org/10.1126/science.231.4735.247, 1986.

Murphy, D. M., Cziczo, D. J., Froyd, K. D., Hudson, P. K., Matthew, B. M., Middlebrook, A. M., Peltier, R. E., Sullivan, A., Thomson, D. S., and Weber, R. J.: Single-peptide mass spectrometry of tropospheric aerosol particles, J. Geophys. Res.-Atmos., 111, 1-15, https://doi.org/10.1029/2006JD007340, 2006. 
Neubauer, K. R., Johnston, M. V., and Wexler, A. S.: On-line analysis of aqueous aerosols by laser desorption ionization, Int. J. Mass Spectrom., 163, 29-37, https://doi.org/10.1016/S01681176(96)04534-X, 1997.

Neubauer, R., Sum, T., Johnston, M. V., and Wexler: Sulfur speciation in individual aerosol particles, J. Geophys. Res., 101, 701707, https://doi.org/10.1029/96JD01555,1996.

Olson, T. M. and Hoffmann, M. R.: On the kinetics of formaldehyde-s(iv) adduct formation in slightly acidic solution, Atmos. Environ., 20, 2277-2278, 1986.

Olson, T. M. and Hoffmann, M. R.: Hydroxyalkylsulfonate formation: its role as a s(iv) reservoir in atmospheric water droplets, Atmos. Environ., 23, 985-997, 1989.

Phinney, L., Richard Leaitch, W., Lohmann, U., Boudries, H., Worsnop, D. R., Jayne, J. T., Toom-Sauntry, D., Wadleigh, M., Sharma, S., and Shantz, N.: Characterization of the aerosol over the sub-arctic north east Pacific Ocean, Deep-Sea Res. Pt. II, 53, 2410-2433, https://doi.org/10.1016/j.dsr2.2006.05.044, 2006.

Pratt, K. A. and Prather, K. A.: Mass spectrometry of atmospheric aerosols-Recent developments and applications. Part I: Off-line mass spectrometry techniques, Mass Spectrom. Rev., 31, 1-16, https://doi.org/10.1002/mas.20322, 2012.

Pratt, K. A., Mayer, J. E., Holecek, J. C., Moffet, R. C., Sanchez, R. O., Rebotier, T. P., Furutani, H., Gonin, M., Fuhrer, K., Su, Y., Guazzotti, S., and Prather, K. A.: Development and Characterization of an Aerosol Time-of-Flight Mass Spectrometer, Anal. Chem., 81, 1792-1800, https://doi.org/10.1021/ac801942r, 2009.

Rao, Z., Chen, Z., Liang, H., Huang, L., and Huang, D.: Carbonyl compounds over urban Beijing: Concentrations on haze and nonhaze days and effects on radical chemistry, Atmos. Environ., 124, 207-216, https://doi.org/10.1016/j.atmosenv.2015.06.050, 2016.

Scheinhardt, S., van Pinxteren, D., Müller, K., Spindler, G., and Herrmann, H.: Hydroxymethanesulfonic acid in sizesegregated aerosol particles at nine sites in Germany, Atmos. Chem. Phys., 14, 4531-4538, https://doi.org/10.5194/acp-144531-2014, 2014.
Shen, X., Lee, T., Guo, J., Wang, X., Li, P., Xu, P., Wang, Y., Ren, Y., Wang, W., Wang, T., Li, Y., Carn, S. A., and Collett, J. L.: Aqueous phase sulfate production in clouds in eastern China, Atmos. Environ., 62, 502-511, https://doi.org/10.1016/j.atmosenv.2012.07.079, 2012.

Song, S., Gao, M., Xu, W., Sun, Y., Worsnop, D. R., Jayne, J. T., Zhang, Y., Zhu, L., Li, M., Zhou, Z., Cheng, C., Lv, Y., Wang, Y., Peng, W., Xu, X., Lin, N., Wang, Y., Wang, S., Munger, J. W., Jacob, D. J., and McElroy, M. B.: Possible heterogeneous chemistry of hydroxymethanesulfonate (HMS) in northern China winter haze, Atmos. Chem. Phys., 19, 1357-1371, https://doi.org/10.5194/acp-19-1357-2019, 2019.

Wang, Y., Zhuang, G., Tang, A., Yuan, H., Sun, Y., Chen, S., and Zheng, A.: The ion chemistry and the source of $\mathrm{PM}_{2.5}$ aerosol in Beijing, Atmos. Environ., 39, 3771-3784, https://doi.org/10.1016/j.atmosenv.2005.03.013, 2005.

Wang, Y., Zhang, Q., Jiang, J., Zhou, W., Wang, B., He, K., Duan, F., Zhang, Q., Philip, S., Xie, Y., Zhang, Q., Jiang, J., Zhou, W., Wang, B., He, K., Duan, F., Zhang, Q., Philip, S. and Xie, Y.: J. Geophys. Res.-Atmos., 119, 10425-10440, https://doi.org/10.1002/2013JD021426, 2014.

Wang, Y., Chen, Z., Wu, Q., Liang, H., Huang, L., Li, H., Lu, K., Wu, Y., Dong, H., Zeng, L., and Zhang, Y.: Observation of atmospheric peroxides during Wangdu Campaign 2014 at a rural site in the North China Plain, Atmos. Chem. Phys., 16, 10985-11000, https://doi.org/10.5194/acp-16-10985-2016, 2016.

Warneck, P.: Sulfur Dioxide in Rain Clouds: Gas-Liquid Scavenging Efficiencies and Wet Deposition Rates in the Presence of Formaldehyde, J. Atmos. Chem., 8, 99-117, 1989.

Whiteaker, J. R. and Prather, K. A.: Hydroxymethanesulfonate as a tracer for fog processing of individual aerosol particles, Atmos. Environ., 37, 1033-1043, https://doi.org/10.1016/S13522310(02)01029-4, 2003.

Zuo, Y. and Chen, H.: Simultaneous determination of sulfite, sulfate, and hydroxymethanesulfonate in atmospheric waters by ion-pair HPLC technique, Talanta, 59, 875-881, https://doi.org/10.1016/S0039-9140(02)00647-1, 2003. 